\title{
Discorrendo Sobre o Uso das Termelétricas no Brasil
}

\author{
Considering on the Use of Thermal Power Plants in Brazil
}

Maria Thereza da Silva Lopes Lima ${ }^{1}$, Marina Corrêa de Souza ${ }^{1}$

${ }^{1}$ Graduandas em Engenharia Química do Instituto de Ciência e Tecnologia, UFVJM, Diamantina, Brasil.

\begin{abstract}
Resumo
O mundo de hoje depende de uma quantidade abundante de energia. Daí, a necessidade de estarmos sempre criando novas formas de obtenção de energia para aumentar a produção industrial e, consequentemente, aumentar a riqueza de um país. Logo, o crescimento industrial está fortemente ligado à maneira de conseguir energia limpa e barata. No Brasil, utiliza-se preferencialmente a energia oriunda das hidrelétricas, mas nem sempre estas podem gerar a demanda energética necessária para suprir todas as nossas carências. Portanto, não podemos negar que as termelétricas possuem um papel respeitável na geração de energia, complementando a energia vinda das hidrelétricas, quando estas passam por momentos de baixa de produção, como em períodos de estiagens.
\end{abstract}

Palavras-chave: Crescimento socioeconômico, efeito estufa, energia elétrica, termelétricas.

\begin{abstract}
Today, the world depends on an abundant amount of energy. Hence, there is a need in creating new ways of obtaining energy to boost industrial production and thereby increase the wealth of a country. Therefore, industrial growth is strongly linked to way to get clean and cheap energy. In Brazil, preferentially uses the energy from the hydroelectric plants, but these may not always generate the energy required to supply all our needs. So, we can not deny that the thermal power plants have a respectable role in power generation, complementing the energy from the hydroelectric when they go through times of low production, as in periods of drought.
\end{abstract}

Keywords: Socioeconomic growth, greenhouse, electric power, thermal power plants. 


\section{Introdução}

A s frequentes mudanças da sociedade demandam uma dependência mais acentuada das fontes de energia para geração de eletricidade. A sociedade brasileira, devido ao seu crescimento socioeconômico acelerado, também segue essa tendência. Dentre essas fontes, estão as renováveis, que possuem capacidade de regeneração em um determinado tempo, tornando-a inesgotável. Como exemplo, podemos citar: a biomassa, a solar, a eólica, a hidráulica, entre outras. Já as fontes não renováveis são caracterizadas a partir de seu tempo de uso, seja num maior ou menor prazo. Inevitavelmente, esse tempo de uso acaba levando essa fonte a um esgotamento. Como exemplo, podemos mencionar: o petróleo e seus derivados, o gás natural, o carvão mineral, o urânio, entre outros. A título de esclarecimento a tonelada equivalente de petróleo (tep) utilizado na tabela abaixo é uma unidade de energia usada para comparar o poder calorífico de inúmeras formas de energia com o poder calorífico do petróleo, especificamente. A relação encontrada é a seguinte: "Uma tep corresponde à energia que se pode obter a partir de uma tonelada de petróleo padrão". (ANEEL, 2008, p. 143).

Tabela 1 - Oferta Interna de Energia no Brasil e Mundo (\% em tep)

\begin{tabular}{|c|c|c|c|c|}
\hline \multirow{2}{*}{ Fonte } & \multicolumn{2}{|c|}{ Brasil } & \multicolumn{2}{c|}{ Mundo } \\
\cline { 2 - 5 } & $\mathbf{1 9 7 3}$ & $\mathbf{2 0 1 3}$ & $\mathbf{1 9 7 3}$ & $\mathbf{2 0 1 3}$ \\
\hline $\begin{array}{c}\text { Petróleo e } \\
\text { Derivados }\end{array}$ & 45,6 & 39,3 & 46,1 & 29,3 \\
\hline Gás Natural & 0,4 & 12,8 & 16 & 21,6 \\
\hline $\begin{array}{c}\text { Carvão } \\
\text { Mineral }\end{array}$ & 3,1 & 5,6 & 24,6 & 30,9 \\
\hline Urânio & 0 & 1,3 & 0,9 & 4,8 \\
\hline $\begin{array}{c}\text { Hidráulica e } \\
\text { Eletricidade }\end{array}$ & 6,1 & 12,5 & 1,8 & 2,3 \\
\hline $\begin{array}{c}\text { Biomassa / } \\
\text { Eólica / Outras }\end{array}$ & 44,8 & 28,5 & 10,6 & 11,1 \\
\hline Total (\%) & 100 & 100 & 100 & 100 \\
\hline $\begin{array}{c}\text { Total - } \\
\text { milhões tep }\end{array}$ & 82 & 296 & 6.115 & 134.482 \\
\hline
\end{tabular}

(Fonte: Ministério de Minas e Energia)

Segundo a publicação do Ministério de Minas e Energia (MME) intitulada "Resenha Energética Brasileira: Exercício 2013", de junho de 2014, nos últimos 40 anos as matrizes energéticas do Brasil e do mundo apresentaram significativas alterações estruturais. No Brasil houve forte aumento na participação da energia hidráulica e do gás natural. (MME, 2014, p. 18).
Chama atenção na matriz mundial o aumento da participação do carvão mineral e o recuo na participação da biomassa/outras. No caso da biomassa, os países em desenvolvimento tendem a substituir lenha por fontes mais nobres e eficientes, como gás liquefeito de petróleo (GLP) e gás natural, principalmente na cocção de alimentos. (MME, 2014, p. 18).

No Brasil, a máxima participação do petróleo e seus derivados na matriz energética ocorreu em 1979 quando atingiu $50,4 \%$. A redução de 6,3 pontos percentuais entre 1973 e 2013, conforme Tabela 1, evidencia que o país, seguindo a tendência mundial, desenvolveu também um esforço significativo para a substituição desses energéticos fósseis. Esse esforço é digno de nota, pois, houve um aumento da geração hidráulica e do uso de derivados da cana como etanol carburante e bagaço, para fins térmicos. (MME, 2014, p. 18).

Vale ressaltar que devido ao aumento do preço do petróleo houve também um maior investimento em pesquisas nas áreas de biocombustíveis, visando substituição de parte do seu uso.

Em termos de presença de fontes renováveis na matriz de energia, é notável a vantagem do Brasil em relação ao resto do mundo, registrando $41,0 \%$ de participação em 2013 , contra $13,4 \%$ no mundo, no que diz respeito ao uso de fontes renováveis. (MME, 2014, p. 19).

Resumidamente, no Brasil, os combustíveis fósseis respondem por $57,7 \%$ da atual matriz energética e no mundo por $81,8 \%$. (MME, 2014, p. 19).

$\mathrm{Na}$ sequência discorreremos brevemente sobre o crescimento energético brasileiro.

\section{O Crescimento Energético Brasileiro}

A crescente necessidade de uso da energia elétrica faz com que sejam intensificadas as buscas por produções eficazes, como é mostrado pela Tabela 1, na qual houve crescimento dos setores de petróleo e derivados, gás natural, carvão mineral, urânio e hidráulica, concomitantemente com um recuo nos setores de biomassa, eólica, outros.

A razão de tal aumento deve-se a construções de grandes indústrias que utilizam grande quantidade de energia elétrica produzida pelo Brasil. Um fato interessante a ser observado é que só existem grandes indústrias perto de grandes centros distribuidores de energia, pois não pode haver indústria sem um polo de produção energética que viabilize sua implementação e principalmente seu funcionamento.

Segundo informações do site Portal Brasil, que se baseiam em fontes do Banco Central, atualmente no Brasil, pode-se constatar um crescimento socioeconômico acelerado, com previsão de crescimento do setor industrial no ano de 2014 subindo de 1,38\% para 1,50\%. Já para o ano de 2015, a previsão de avanço industrial foi mantida em 3,00\%. (PORTAL BRASIL, 2014). 
Tais análises nos permitem inferir que existe a necessidade de aumentar o fornecimento de energia elétrica. Conforme dito anteriormente, as hidrelétricas são responsáveis pela maior parte da energia produzida no Brasil. Porém, nem sempre elas estão funcionando a $100 \%$ de sua capacidade devido a estiagens que estão se tornando cada vez mais comuns em nosso país. Ainda, servindo como válvula de escape, as termelétricas assumem um papel importante na geração de energia quando as hidrelétricas estão comprometidas.

Entretanto, as termelétricas utilizam combustíveis fósseis, tais como carvão mineral, derivados do petróleo e gás natural que contribuem para o efeito estufa, pois depois de serem queimados, liberam dióxido de carbono para a atmosfera.

Precisamos agora definir e entender a dinâmica das usinas termelétricas a fim de averiguar se as mesmas são boas substitutas para usinas hidrelétricas.

\section{As Usinas Termelétricas}

Uma usina termelétrica é uma planta química que produz energia a partir do calor gerado pela queima de combustíveis fósseis ou por outras fontes de calor, como, por exemplo, a fissão nuclear. O combustível que será consumido seja o fóssil, seja o urânio, será armazenado em parques ou depósitos próximos às usinas. A fonte de calor oriunda da queima dos combustíveis é responsável pelo aquecimento de uma caldeira cheia d'água, gerando vapor d'água em alta pressão. Consequentemente, o vapor sob alta pressão e temperatura, se expande e movimenta as pás da turbina do gerador, produzindo a energia elétrica final. Assim, essa energia é transportada por linhas de alta tensão até os centros de consumo.

Após o vapor d'água ter movimentado as turbinas, ele é enviado a um condensador para ser resfriado e, logo em seguida, transformado em água líquida para ser reenviado à caldeira, iniciando um novo ciclo. Esse vapor pode ser resfriado utilizando a água de um rio, um lago ou um mar, mas esse processo de resfriamento causa danos ecológicos devido ao aquecimento da água e, consequentemente, uma diminuição da concentração do oxigênio dissolvido. Outra maneira de resfriar esse vapor é utilizando água armazenada em torres. No final do processo, esta água é enviada em forma de vapor à atmosfera, podendo alterar o regime de chuvas.

Em comparação com as usinas hidrelétricas, as termelétricas são mais rápidas de se construir, e conforme Braciani, "[...] isso se deve as características técnicas e econômicas desse tipo de empreendimento, disponibilidade de combustíveis e o menor valor de implantação, [...]" (BRACIANI, 2011, p. 60). Podendo assim suprir carências de energia de forma mais rápida. Além disso, as termelétricas podem ser construídas próximas a centros urbanos, diminuindo as linhas de transmissões e desperdiçando menos energia.
No Brasil, utiliza-se a energia termelétrica de forma estratégica, pois esta pode ser produzida em uma quantidade constante durante o ano inteiro, diferentemente das hidrelétricas, as quais possuem a produção dependente do nível de rios. Mais especificamente, as termelétricas complementam a matriz energética das hidrelétricas, sendo acionadas predominantemente quando há necessidade, como em períodos de estiagem.

Para minimizar os efeitos contaminantes da combustão sobre o entorno das termelétricas, sua central dispõe de uma chaminé de grande altura, algumas chegam a 300 metros, e de alguns precipitadores que retêm as cinzas e outros resíduos voláteis da combustão. Conforme o site Ambiente Brasil, as cinzas, algumas vezes, são recuperadas para o aproveitamento em processos de metalurgia e no campo da construção civil, nos quais são misturadas com o cimento. (AMBIENTE BRASIL).

Após a queima dos combustíveis fósseis, gases são soltos na atmosfera causando grandes impactos ambientais, contribuindo para o aquecimento global através do efeito estufa e de chuvas ácidas.

Mais uma desvantagem é o custo final deste tipo energia. Ele é mais elevado do que o custo da energia gerada em hidrelétricas, em função do preço dos combustíveis fósseis utilizados.

Outrossim, as usinas térmicas não são propriamente eficientes, apenas aproximadamente $38 \%$ da energia térmica colocada na usina pelo combustível torna-se aproveitável como a energia elétrica, segundo dados do site Ambiente Brasil. (AMBIENTE BRASIL).

\section{Refletindo Sobre as Termelétricas}

Indaga-se, portanto, o seguinte ponto: porque não utilizar outros combustíveis, como por exemplo, o bagaço da cana de açúcar ou urânio enriquecido para a geração dessa energia?

As razões são várias. A geração de eletricidade pela queima do bagaço de cana ainda geraria dióxido de carbono e sua eficiência comparada a dos combustíveis fósseis é inferior, isso porque de acordo com Innocente (2011, p.36), apenas as fibras presentes na composição da cana, de 8 a 14\% (COPERSUCAR apud INNOCENTE, 2011, p.27), contribuem para a produção calorífica. Entretanto, o fator que mais colabora para a redução de eficiência de queima, quando comparada, por exemplo ao óleo combustível, é a sua umidade, próxima a 50\% da constituição total, ainda segundo Innocente (2001, p. 43).

A outra opção seria a utilização do urânio, através da energia nuclear que infelizmente ainda é considerada um tabu na sociedade brasileira. Isso porque se trata de um assunto não conhecido em sua plenitude por grande parte da população. As pessoas a veem como uma forma de obtenção de energia perigosa graças à influência das mídias que a associam aos acidentes ocorridos pelo mundo. Podemos citar o acidente de Chernobyl em 
1986; e, o de Fukushima em 2011. Ambos os acidentes não tiveram nada a ver com a manipulação da energia nuclear em si, mas foram causados por erros humanos, tsunamis e terremotos.

\section{Sobre os Tipos de Combustíveis Utilizados em Termelétricas}

\subsection{Gás Natural}

O gás natural é um dos combustíveis fosseis mais utilizados no Brasil. Com base nas informações do site Câmara de Comercialização de Energia Elétrica (CCEE), sendo o gás natural uma mistura de hidrocarbonetos gasosos, originados da decomposição de matéria orgânica fossilizada ao longo de milhões de anos, possui elevado poder calorífico e, em sua queima, apresenta baixos índices de emissão de poluentes, em comparação a outros combustíveis fósseis. Em caso de vazamentos, tem rápida dispersão, com baixos índices de odor e de contaminantes. (CCEE).

O funcionamento de uma usina termelétrica que utiliza gás natural como combustível é explicado a seguir pela publicação da Agência Nacional de Energia Elétrica (ANEEL), intitulada de "Atlas de Energia Elétrica do Brasil"

"A aplicação do gás natural na produção de energia elétrica pode ser dividida em duas modalidades. Uma delas é a geração exclusiva da eletricidade. Outra é a cogeração, da qual se extrai também o calor e o vapor utilizados em processos industriais. Nas usinas termelétricas, a primeira etapa do processo consiste na mistura de ar comprimido com o gás natural a fim de se obter a combustão. O resultado é a emissão de gases em alta temperatura, que provocam o movimento das turbinas conectadas aos geradores de eletricidade. Portanto, a energia térmica transforma-se em mecânica e, em seguida, em elétrica. $\mathrm{O}$ destino dado ao gás natural após esta aplicação determina se o ciclo da termelétrica será simples ou aberto, combinado ou fechado. No primeiro caso, o mais tradicional, os gases são resfriados e liberados na atmosfera por meio de uma chaminé. No ciclo combinado, ainda em alta temperatura, os gases são transformados em vapor que direcionado às turbinas, novamente provoca o seu movimento. Assim, a característica básica das termelétricas de ciclo combinado é a operação conjunta de turbinas movidas a gás e a vapor." (ANEEL, 2008, p. 94).

Em consonância com o site da CCEE, o desenvolvimento deste tipo de geração é relativamente recente, data do início da década de 1940. O uso dessa tecnologia foi ampliado somente na última década do século passado. (CCEE).

No Brasil, a matriz da energia elétrica é predominantemente hidráulica e esta característica não deverá se alterar a médio prazo. No entanto, de acordo com o Plano Nacional de Energia 2030 produzido pela Empresa de Pesquisa Energética (EPE), a participação das termelétricas movidas a gás natural deveria aumentar, a curto e médio prazo, mas não é bem assim. Essas usinas operariam de maneira complementar às hidrelétricas. Em outras palavras, seriam colocadas em operação em momentos de acentuado aumento de demanda ou redução da oferta hidráulica, por exemplo, nos períodos de estiagem, onde seria necessário preservar os reservatórios. (EPE apud ANEEL, 2008, p. 101).

Entre as vantagens adicionais da geração termelétrica a gás natural estariam o prazo relativamente curto de maturação do empreendimento e a flexibilidade para o atendimento de cargas de ponta. (ANEEL, 2002, p. 91).

\subsection{Petróleo e Derivados}

Outro combustível muito utilizado é o petróleo, uma mistura de hidrocarbonetos que tem origem na decomposição de matéria orgânica, principalmente o plâncton que são plantas e animais microscópicos em suspensão nas águas, causada pela ação de bactérias em meios com baixo teor de oxigênio, no entendimento do site da CCEE. (CCEE).

Embora conhecido desde os primórdios da civilização humana, somente em meados do século XIX tiveram início a exploração de campos e a perfuração de poços de petróleo. A partir de então, a indústria petrolífera teve uma grande expansão. Apesar da forte concorrência do carvão e de outros combustíveis considerados nobres para a época, o petróleo passou a ser utilizado em larga escala, especialmente após a invenção dos motores a gasolina e a óleo diesel. (ANEEL, 2002, p. 75).

Durante muitas décadas, o petróleo foi o grande propulsor da economia mundial, chegando a representar, no início dos anos 1970, quase 50\% do consumo de energia primária em todo o mundo. (ANEEL, 2002, p. 75). Embora o petróleo esteja em declínio, sua participação nesse consumo ainda representa cerca de $43 \%$, segundo dados da Agência Internacional de Energia, de 2003.

A participação do petróleo na produção mundial de energia elétrica é pouco expressiva e tem recuado nos últimos anos, em decorrência dos investimentos realizados na utilização de outras fontes, menos agressivas ao meio ambiente e com preços menores e mais estáveis. Os derivados mais utilizados são óleo diesel, óleo combustível, gás de refinaria e, com menor frequência, o óleo ultraviscoso, cuja combustão produz o vapor necessário à movimentação das turbinas. (ANEEL, 2008, p. 113).

No Brasil, as termelétricas movidas a derivados de petróleo, nas palavras do Atlas da ANEEL, “apresentam maior valor agregado se utilizados em transportes ou geração distribuída". (ANEEL, 2008, p.113). Por isso, sua participação na matriz da energia elétrica é pequena. 
"As usinas abastecidas por óleo diesel estão instaladas principalmente na região Norte para atender os Sistemas Isolados que ainda não são conectados ao Sistema Interligado Nacional (SIN), rede composta por linhas de transmissão $e$ usinas que operam de forma integrada e abrangem a maior parte do território do país. Os maiores são Acre-Rondônia, Manaus e Macapá. No médio prazo, eles serão conectados ao SIN por meio da construção de linhas de transmissão. Consequentemente, essas termelétricas poderão vir a ser desativadas, principalmente as de menor porte ou de baixa eficiência. Os custos do óleo utilizado são repassados a todos os consumidores de energia elétrica do país por meio do encargo Conta de Consumo de Combustíveis (CCC) embutido na tarifa final. A maior parte das demais usinas opera com óleo combustível ou gás de refinaria e está distribuída por todo o território nacional, com ênfase para a região Sudeste. Todas são complementares ao sistema hidrelétrico." (ANEEL, 2008, p. 113).

\subsection{Carvão Mineral}

Na ideia contida no site da CCEE, o carvão, a exemplo do que ocorre com os demais combustíveis fósseis, é uma complexa e variada mistura de componentes orgânicos sólidos, fossilizados ao longo de milhões de anos. (CCEE). Nas palavras do Atlas da ANEEL, sua qualidade, determinada pelo conteúdo de carbono, varia de acordo com o tipo e o estágio dos componentes orgânicos, a saber: a) a turfa, de baixo conteúdo carbonífero, constitui um dos primeiros estágios do carvão, com teor de carbono na ordem de $45 \%$; b) o linhito apresenta um índice que varia de $60 \%$ a $75 \%$; c) o carvão betuminoso ou hulha, mais utilizado como combustível, contém cerca de $75 \%$ a $85 \%$ de carbono é um dos mais puros carvões; e; d) o antracito apresenta um conteúdo carbonífero superior a 90\%. Da mesma forma, os depósitos variam de camadas relativamente simples e próximas da superfície do solo e, portanto, de fácil extração e baixo custo, a complexas e profundas camadas, de difícil extração e custos elevados. (ANEEL, 2002, p. 81).

Dadas as informações retiradas do site da CCEE, o aproveitamento do carvão mineral para a geração de energia elétrica no Brasil teve início nos anos 1950. (CCEE). Nas palavras do Atlas da ANEEL:

"O carvão é uma das formas de produção de energia mais agressivas ao meio ambiente. Ainda que sua extração e posterior utilização na produção de energia gerem benefícios econômicos, como empregos diretos e indiretos, aumento da demanda por bens e serviços na região e aumento da arrecadação tributária, o processo de produção, da extração até a combustão provoca significativos impactos socioambientais. (ANEEL, 2008, p. 140)."

\subsection{Termonuclear}

A termonuclear ou usina nuclear é uma instalação industrial que tem por finalidade produzir energia elé- trica a partir de reações nucleares.

Existem duas formas de aproveitar a energia proveniente de reações nucleares para a produção de eletricidade, a saber: a fissão nuclear, na qual o núcleo atômico se divide em duas ou mais partículas; e a fusão nuclear, na qual dois ou mais núcleos se unem para produzir um novo elemento, segundo dados do site da Eletrobras. (ELETROBRAS). Ambas as reações nucleares mencionadas produzem uma grande quantidade de energia térmica.

A tecnologia disponível atualmente é a fissão do átomo de urânio, sendo a principal técnica empregada para a geração de eletricidade em usinas nucleares. Ainda segundo informações do site da Eletrobras, a tecnologia é usada em mais de 400 centrais nucleares em todo o mundo, principalmente em países como França, Japão, Estados Unidos, Alemanha, Suécia, Espanha, China, Rússia, Coréia do Sul, Paquistão e Índia, entre outros. (ELETROBRAS).

O funcionamento de uma termonuclear é bastante semelhante ao funcionamento de usinas termelétricas. A fissão dos átomos de urânio dentro das varetas do elemento combustível aquece a água a $320^{\circ} \mathrm{C}$ que passa pelo reator. Para que a água não entre em ebulição, o que ocorreria normalmente aos $100^{\circ} \mathrm{C}$, ela é mantida sob uma pressão 157 vezes maior que a pressão atmosférica. O gerador de vapor realiza uma troca de calor entre as águas deste primeiro circuito e a do circuito secundário, independentes entre si. Com essa troca de calor, a água do circuito secundário se transforma em vapor e movimenta a turbina a uma velocidade de $1.800 \mathrm{rpm}$ que, por sua vez, aciona o gerador elétrico.

Esse vapor, depois de mover a turbina, passa por um condensador, onde é refrigerado pela água de um reservatório, trazido por um terceiro circuito independente, segundo informações fornecidas pelo site da Eletrobras. (ELETROBRAS). A existência desses três circuitos impede o contato da água que passa pelo reator com as demais, evitando assim a contaminação com a radioatividade liberada pela fissão do urânio.

No entendimento da Eletrobras, a maior vantagem ambiental da geração elétrica através de usinas nucleares é a não utilização de combustíveis fósseis, evitando o lançamento na atmosfera dos gases responsáveis pelo aumento do aquecimento global e outros produtos tóxicos. Outro benefício é o fato de as usinas nucleares ocuparem áreas relativamente pequenas, podendo ser instaladas próximas aos centros consumidores e não dependem de fatores climáticos, como chuva ou vento para o seu funcionamento. (ELETROBRAS).

Segundo a publicação do Ministério de Minas e Energia descrito em o "Plano Nacional de Energia 2030: Geração Termonuclear":

"As duas maiores preocupações de caráter socioambiental com a operação de usinas nucleares são o risco de um acidente nos moldes de Chernobil e a disposição dos dejetos 
nucleares. Por outro lado, vem crescendo a preocupação com o aumento do efeito estufa e as mudanças climáticas, o que aumenta o interesse pelas usinas nucleares, além de não emitir CO2. [...] Os acidentes ocorridos em Three Miles Island e Chernobil provocaram uma revisão nos procedimentos operacionais e de segurança. As técnicas de segurança passiva, pelas quais, em falha, o sistema vai para uma situação segura, também contribuem para minimizar o risco de catástrofe, embora não o afaste." (MME, 2006-2007, p.71).

O problema mais grave da utilização de usinas nucleares é o destino do chamado lixo atômico separado segundo a sua atividade radioativa: alta, média ou baixa. Sendo que o maior problema é a duração desta atividade que se prolonga por milhares de anos, deixando para as gerações futuras o gerenciamento do problema. (MME, 2006-2007, p.72).

A entrada em vigor do Protocolo de Kioto (PNUD, 2005), ainda que com aprovação de países responsáveis por apenas $62 \%$ das emissões, traz novo alento à geração de eletricidade por fissão nuclear, não emissora de gases de efeito estufa. (MME, 2006-2007, p.71).

\section{Conclusão}

Retomando nosso objetivo, a crescente necessidade e uso da energia elétrica faz com que sejam intensificadas as buscas por outras produções eficazes. De modo geral, almejamos que essas novas produções possam englobar abundância e continuidade, além da máxima redução de danos, sejam eles ambientais e/ou sociais. A escassez de chuvas, a poluição proporcionada pela queima de combustíveis fósseis e a dependência do Brasil em importar parte desse combustível são as principais razões de se pensar em uma solução capaz de produzir quantidades equivalentes de energia. Essa nova energia não deveria depender do clima que vem apresentando inconstâncias, nem dos preços externos para obtenção do combustível utilizado, além de não ser prejudicial ao meio ambiente e à população.

Em um país previamente conhecido como um grande detentor de fontes hidráulicas para produção de energia elétrica, cremos haver um grande campo para a utilização de fontes termelétricas, conforme a seguinte assertiva:

"Em um sistema elétrico de base hidráulica, a flexibilidade de aquisição e uso do combustível térmico é uma característica desejável do regime operativo das termelétricas. Além disso, quanto mais flexível for esse regime operativo, maior tende a ser a competitividade da geração termelétrica, pela apropriação possível do "excedente" hidráulico em períodos de hidrologia favorável." (MME, 2006-2007, p.68).

Em suma, a lógica econômica impõe que essas usinas devam permanecer praticamente desligadas nos períodos de abundância hidrológica, gerando energia elétrica apenas nos períodos em que as afluências e o estoque de água dos reservatórios são insuficientes para o atendimento da carga. Esse regime operacional é denominado complementar. (MME, 2006-2007, p.68).

A análise que pode ser feita pela leitura do texto acima revela que quanto mais rentável for a forma de obtenção de energia, maior a chance de ser aceita e utilizada. $\mathrm{Na}$ verdade, o que conta é a tecnologia vigente em cada projeto. Logo, a tecnologia mais avançada acarretará um maior encargo ao preço final da energia utilizada.

Porém, de acordo com Braciani, considerando os custos, tais como: combustível, operação, manutenção e emissão de poluentes, o custo total da usina termelétrica, no decorrente de sua produção será muito mais onerosa quando comparada a uma hidrelétrica. Cabe ressaltar que os custos de cada empreendimento estão diretamente conectados às alternativas tecnológicas. (BRACIANI, 2011, p. 61).

Nas palavras de Boarati; Shayani, o grau de competitividade das termelétricas é um fator importante para contrabalançar o atraso dos investimentos em geração elétrica. O sistema está com riscos de déficit de energia, devido aos baixos índices pluviométricos nas principais regiões que possuem hidrelétricas, juntamente com o retardo em novos investimentos. Outros fatores importantes e que também contribuíram foram o crescimento da economia e o aumento de consumo. Em função disso, ações a curto prazo devem ser tomadas sem demora. Como o tempo de construção de uma termelétrica é inferior ao de uma hidrelétrica, esta opção torna-se muito mais do que atrativa: ela é fundamental para não comprometer a confiabilidade do fornecimento. $\mathrm{O}$ gás natural é o combustível mais amplamente utilizado por estas usinas, as quais irão explorar o gasoduto Brasil-Bolívia o máximo possível. (BOARATI; SHAYANI, 1998, p. 53). Para Luiz Pinguelli Rosa:

"A existência de um problema foi reconhecida quando a Agência Nacional de Energia Elétrica (Aneel) retirou várias termelétricas do plano de operação por não disporem de gás para operar, segundo a Petrobras. [...] A resolução da Aneel revelou que o risco de déficit de energia é bem maior do que se calculava. Houve uma polêmica com o Ministério de Minas e Energia e determinou-se que as termelétricas operassem por tempo limitado em teste. O resultado do teste foi pior que o esperado. Pediu-se à Petrobras para remanejar o gás de outros usuários. [...] Há o problema dos contratos usuais, nos quais se paga pelo uso de gás sem interrupção. Antes mesmo da crise da Bolívia, a Petrobras estudava a importação de gás natural liquefeito por navios que pode ser interrompida conforme a necessidade. O problema é que leva tempo para implantar uma usina de regaseificação. Pensa-se em adaptar termelétricas para serem bicombustíveis, podendo usar diesel ou outros combustíveis no lugar de gás. Mas eles são muito mais caros. [...] A alta do preço internacional do petróleo repercute no 
gás natural e, portanto, na geração elétrica - embora hoje, a participação do petróleo na economia mundial seja menor do que nos tempos dos choques dos anos de 1970. Em âmbito mundial, essa participação nos custos dos produtos em geral é a metade do que era naquele tempo."(ROSA, L. P., 2011, p. 43-44).

Diante desses fatos, o ponto de partida mais coerente para a execução de projetos de usinas termelétricas é a definição do tipo de combustível, desde a sua disponibilidade até a viabilidade econômica, passando pelo estudo das características físicas e químicas. Fazendo um estudo completo do projeto, tem-se a chance de reduzir gastos e tornar a termelétrica uma forma de obtenção de energia, não mais apenas como uma complementar da matriz energética.

Finalizando, para obtermos uma visão panorâmica da situação atual, apresentamos em anexo, um quadro comparativo entre os tipos de termelétricas mencionados ao longo do presente artigo. Nosso objetivo é tão somente clarificar as características dos tipos de termelétricas selecionados. (Ver arquivo suplementar).

\section{Agradecimentos}

Agradecemos ao Professor Rubens Martins Moreira do Centro de Desenvolvimento de Tecnologia Nuclear (CDTN) por nos receber e nos incentivar a defender e divulgar a energia nuclear.

Agradecemos ao Professor Alexandre C. Tort, do Instituto de Física da UFRJ, pelas correções, sugestões e paciência, com o nosso excesso de entusiasmo.

Agradecemos a Professora Socorro Lima Costa do Departamento de Ciências Biológicas por abraçar nosso projeto.

Agradecemos à FAPEMIG e ao CNPq, sem os quais esta pesquisa não poderia ser realizada.

Agradecemos ao Instituto de Ciência e Tecnologia (ICT) da UFVJM e a Pró-reitoria de Pesquisa e Pósgraduação da UFVJM pelo apoio logístico e confiança.

\section{Referências}

AGÊNCIA NACIONAL DE ENERGIA ELÉTRICA. (Brasília, DF). Atlas de Energia Elétrica do Brasil. Brasília, 2002.

.(Brasília, DF). Atlas de Energia Elétrica do Brasil. 3 ed. Brasília, 2008.

AMBIENTE BRASIL. Usinas Termelétricas. Disponível em: <http://ambientes.ambientebrasil.com.br/energia/ termeletrica/usina_termeletrica.html>. Acesso em: 21 ago. 2014.
BOARATI, J. H.; SHAYANI, R. A. Hidrelétricas e Termelétricas a Gás Natural Estudo Comparativo Utilizando Custos Completos. 1998. 177 f. Monografia Departamento de Engenharia de Energia e Automação Elétricas da Escola Politécnica da Universidade de São Paulo, São Paulo, 1998.

BRACIANI, U. Estrutura de Custos para Implantação das Usinas de Geração de Energia Elétrica no Brasil. 2011. 84 f. Monografia (Bacharel em Ciências Econômicas) Departamento de Ciências Econômicas, Universidade Federal de Santa Catarina, Florianópolis, 2011.

CÂMARA DE COMERCIALIAÇÃO DE ENERGIA ELÉTRICA (CCEE). Fontes. Disponível em: <http:// www.ccee.org.br/portal/faces/pages_publico/ondeatuamos/fontes?_adf.ctrl-state $=$ hpgkfbnjb_4\&_ afr L o o p = 342196405631456\#\% 40\%3 F_ afrLoop\%3D $342196405631456 \% 26$ _adf. ctrl-state\%3Di8s3fs1po_4>. Acesso em: 18 ago. 2014.

COMISSÃO NACIONAL DE ENERGIA NUCLEAR (CNEN). Apostila Educativa: Energia Nuclear.

COMPANHIA ENERGÉTICA DE MINAS GERAIS (CEMIG). Alternativas Energéticas: uma visão CEMIG. Belo Horizonte, 2012.

ELETROBRAS. Energia Nuclear. Disponível em: $<$ http://www.eletronuclear.gov.br/Saibamais/ Espa\%C3\%A7odoConhecimento/Pesquisaescolar/ EnergiaNuclear.aspx>. Acesso em: 30 ago. 2014.

INNOCENTE, A. F. Cogeração a partir da biomassa Residual de cana-de-açúcar - Estudo de Caso. 2011. 111 f. Dissertação (Mestrado em Agronomia) - Faculdade de Ciências Agronômicas, Universidade Estadual Paulista, Botucatu, 2011.

MINISTÉRIO DE MINAS E ENERGIA (MME). Plano Nacional de Energia 2030. Brasília, 2006-2007.

. Plano Nacional de Energia 2030: Geração Termonuclear. Brasília, 2006-2007. p. 68; 71-72.

Resenha Energética Brasileira: Exercício de 2013. Brasília, 2014. p. 18-19.

PORTAL BRASIL. Projeção para crescimento industrial do País salta de 1,38\% para 1,50\%, diz Banco Central. Abril, 2014. Disponível em: <http://www.brasil.gov. br/economia-e-emprego/2014/04/projecao-paracrescimento-industrial-do-pais-salta-de-1-38-para1-50-diz-banco-central>. Acesso em: 05 set. 2014.

ROSA, L. P. Geração Hidrelétrica, Termelétrica e Nuclear. Estudos Avançados. v. 21, n.59. p. 43-44. 2007. 